\title{
Farmer's Bookshelf: A Computerized Hypermedia Information System for Crops
}

Kent D. Kobayashi ${ }^{1}$ and H.C. Bittenbender ${ }^{1}$

Additional index words. computer, hypertext, extension, HyperCard, Hawaii

Summary. A computerized personal information management system has been developed to provide information on crop production and industry status to extension personnel and farmers. This hypermedia system, which links interrelated facts, enables the user to browse easily through a mass of information and access specific data rapidly.

$\mathrm{F}$ armers need up-to-date information on production practices and industry status to make sound management decisions. Information usually comes from other farmers, extension specialists, and agents. Published sources include extension bulletins, proceedings of commodity group meetings and workshops, and, in Hawaii, the "Industry Analysis" (Bittenbender et al., 1988). These methods do have shortcomings. With many clientele, it may be difficult for extension personnel to service everyone adequately. Information presented at annual commodity group meetings may be late getting to the farmers. If the material is lengthy, it can be frustrating for the reader to find a specific topic. Extension publications become outdated or out of print. In Hawaii, a commodity industry analysis is published only every 3 years.

Up-to-date information is needed in a simple and easily accessible form. We wanted to develop a computerized information system that could present current information to extension personnel and farmers in a straightforward format. Such a computerized information system that uses HyperCard (Apple Computer Co., Cupertino, Calif.) on an Apple Macintosh computer is the "Farmer's Bookshelf" (Bittenbender and Kobayashi, 1989).

Program development. HyperCard is an information management program based on the principles of "hypermedia" and "hypertext," Hypermedia is the delivery of information that is cross-referenced with interlinked facts (Goodman, 1987); hypertext is a body of written and pictorial material interconnected in a complex way (Nelson, 1965). Information is sometimes so interconnected that it is more effective and convenient to have it in a hypermedia format for easier access. Hypermedia has been used to present information on how to select landscape plants (Taylor et al., 1990) and to run biological simulation models (Schnase and Leggett, 1989).

HyperCard uses the index card idea with information being stored on a group of "cards" called a "stack." A card

${ }^{\prime}$ Department of Horticulture, University of Hawaii at Manoa, Honolulu, HI 96822 Hawaii Institute of Tropical Agriculture and Human Resources Journal Series 3537. The use of trade names does not imply endorsement of the named products over similar ones. 


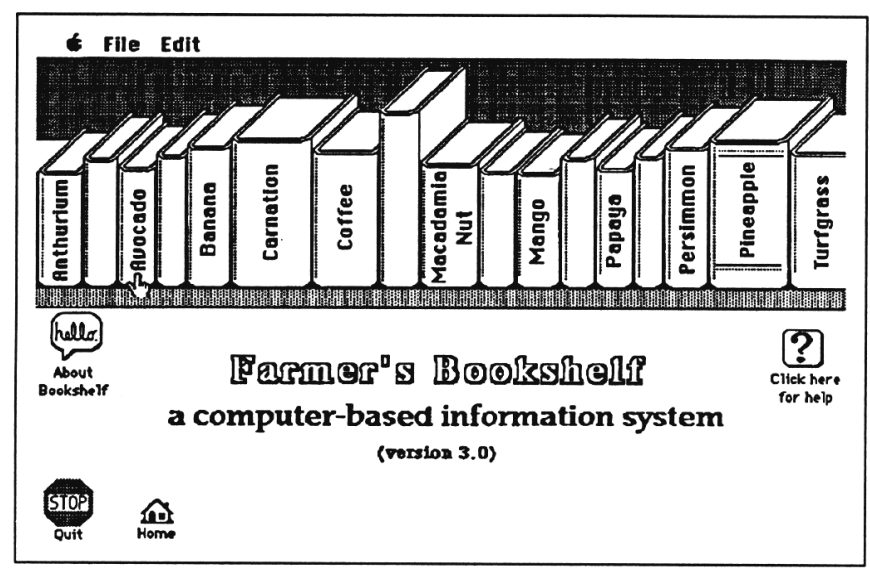

Fig. 1. The BOOKSHELF stack (file) of the Farmer's Booksbelf displays tbe names of various crops. Each book is linked to a stack containing information on tbat crop. The user moves tbe cursor (a band witb a pointing finger) over tbe name of the crop (e.g., avocado) and presses tbe mouse button. This takes the user to the stack on that crop. Otber buttons provide instructions and background information on tbe Farmer's Booksbelf.

is a computer-screen-sized workspace that contains text and graphics (Fig. 1). Objects on a card (e.g., a word or picture) can be used to link that card to another card. By selecting an object with the cursor and pressing the mouse button, users navigate from card to card.

We designed the cards in a stack to look similar to each other (Apple Computer, 1989) to avoid confusion and to navigate easily through the stack. Painting and drawing tools in HyperCard were used to draw the background and headings on the cards. "Buttons" then were added to the cards (Fig. 2). A button is an object on a card that when "clicked" (moving the cursor over the button and pressing the mouse button) causes a set of instructions to be executed. Added to the background of the cards were "fields," areas that hold up to $32 \mathrm{~kb}$ of textual information (Fig. 3). HyperTalk (Shafer, 1988), the programming language of HyperCard, was used to write the instructions for buttons and fields to carry out specific actions. Portions of a word processing file of an industry analysis (Bittenbender et al., 1988) were "cut and pasted" electronically into the fields on the cards.

Use of program. The Farmer's Bookshelfruns on an Apple Macintosh Plus, SE, or II computer. A computer with a hard drive and a floppy drive is recommended. One megabyte of RAM and the HyperCard program itself are needed.

The Farmer's Bookshelf currently has 14 stacks: a bookshelf stack, stacks of 11 crops, a stack for computing macadamia nut losses (Kobayashi and Bittenbender, 1989), and a stack for diagnosing common problems of macadamia nut (Kobayashi et al., 1991). The main stack, containing only one card, is called the BOOKSHELF stack (Fig. 1). On this card the user chooses a particular crop (book) from a group of crops (titled books on the bookshelf). Each titled book on the bookshelf is linked to a stack of cards for that crop.

When a crop is chosen the program goes to the stack for that crop. Each stack for a crop contains two card "backgrounds." A background is a layout shared by one or more cards. The first card of the stack, the TOPICS card, is the table of contents that displays the various topics on a crop (Fig. 2). The remaining cards are CHAPTER cards containing the textual and graphic information on specific topics (Fig. 3). Choosing a topic by clicking its button takes the user from the TOPICS card to a CHAPTER card.

CHAPTER cards have scrollable windows of text with vertical arrows to view more text than is shown in the field at once. Moving forward or backward through the cards is done by clicking the horizontal directional arrows at the bottom of the card (Fig. 3). While viewing a card, the user has several options; e.g., printing the text or saving it to a disk file. Using a find feature, the user may search for a particular word or phrase. Clicking the name of another topic in a field of topics takes the user to that topic (Fig. 3).

Program evaluation. The Farmer's Bookshelf has been shown to a wide range of audiences, including farmers at commodity group meetings, extension personnel, and researchers. The Farmer' s Bookshelfis distributed currently via disks to county extension offices, commodity organizations, and individual farmers. It also is available on the College of Tropical Agriculture and Human Resources' electronic bulletin board "The Coconut Telegraph" and the national information services CompuServe (Columbus, Ohio) and GEnie (Rockville, Md.). A copy of the Farmer's Bookshelfmay be obtained by contacting the senior author.

The Farmer's Bookshelf also does spreadsheet-like calculations for computing costs and amount of losses from macadamia nut spoilage (Kobayashi and Bittenbender, 1989). Another stack keeps track of farmers and their individual orchards. It links these orchards to Microsoft Excel spreadsheets and graphs of nutrient levels over time. A recently added stack can diagnose $\approx 23$ common problems of macadamia nut (Kobayashi et al., 1991). Plans include expanding the Farmer's Bookshelf to include other crops such as coffee and guava.

The Farmer's Bookshelfoffers several advantages to the user. By simply moving the cursor and pressing the mouse button, it is in operation. It offers various presentation formats, including text, graphics, animation, calculations, and sound. Updates are made by editing the information on an existing card or pasting in new information from a word processing file. The basic crop stack (Figs. 2 and 3) can be used as a template for creating stacks for other crops

+ File Edit Go Tools objects

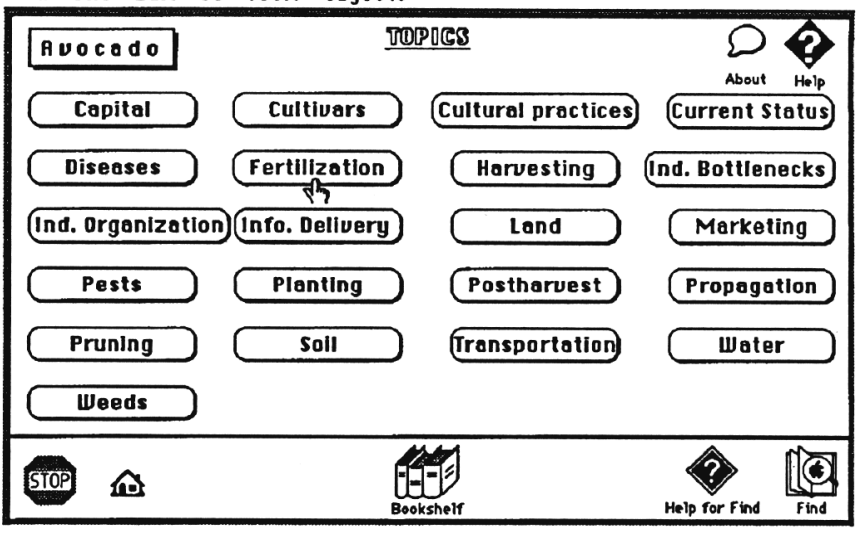

Fig. 2. The TOPICS card of the Farmer's Bookshelf shows the various topics of information on a particular crop. The user clicks on the name of a topic to go to the card on that topic (e.g., fertilisation). The user may search for specific words in the stack using the find feature. 
* File Edit Go Tools Objects

\begin{tabular}{|l|l|l|l|}
\hline \multicolumn{1}{|c|}{ Frocado } & \multicolumn{1}{|c|}{ Fertilization } \\
\hline a. This is a partial summery of "Fertilizetion of Avocedo & \multicolumn{1}{|c|}{ Topics } \\
Trees" (HITAHR Commodity Foct Sheet Avo 3 (B), 1988, \\
available from any Hawail Cooperative Extension Service \\
office.
\end{tabular}

Fig. 3. The CHAPTER card of the Farmer's Bookshelf shows a field containing information on a particular topic. The user can use the pertical arrows on the right side of the field to scroll for more information. The user can go to cards of other topics by clicking on theirnames in the field of topics (e.g., pruning). Information in the field may be printed or saved to a disk.

(Schnase and Leggett, 1989). The Farmer's Bookshelf offers the user a computerized format to browse through and access information quickly and easily.

\section{Literature Cited}

Apple Computer, Inc. 1989. HyperCard stack design guidelines. Addison-Wesley, New York.

Bittenbender, H.C., N. Kefford, K.G. Rohrbach, and W.T. Harada (eds.). 1988. Macadamia industry analysis number 4. Hawaii Inst. of Trop. Agr. and Human Resources, Univ. of Hawaii, Honolulu.

Bittenbender, H.C. and K.D. Kobayashi. 1989. Farmer's Bookshelf, A computer-based information system on fruit crops in Hawaii. Hawaii Inst. Trop. Agr. Human Resources Brief 75.

Goodman, D. 1987. The complete HyperCard handbook. Bantam, New York.

Kobayashi, K.D. and H.C. Bittenbender. 1989. Calculating total nut spoilage losses of macadamia with the Farmer's Bookshelf. Proc. 29th Annu. Mtg. Hawaii Macadamia Nut Assn., KailuaKona, Hawaii, 6 May 1989. p. 47-51.

Kobayashi, K.D., H.C. Bittenbender, and H.H. Hirae. 1991. Hypermedia information system for diagnosing common problems of macadamia nut. J. Hawaii Pacific Agr. (In press.)

Nelson, T.H. 1965. A file structure for the complex, the changing, and the indeterminate. Proc. 20th Natl. ACM Conf. p. 84-100.

Schnase, J.L. and J.J. Leggett. 1989. Computational hypertext in biological modelling. Hypertext ' 89 Proc., 5-8 Nov. 1989. Pittsburgh, Assn. for Computing Machinery, New York. p. 181-197.

Shafer, D.G. 1988. HyperTalk programming. Hayden, Indianapolis.

Taylor, K.H.S., G. Cobb, and J. Zajicek. 1990. A HyperCard application for the selection of southern landscape plants. HortScience 25:1111. (Abstr.) 